\title{
Changes in respiratory drive account for the magnitude of dyspnoea during bronchoconstriction in asthmatics
}

\author{
S. Bellofiore*, F.L.M. Ricciardolo+, N. Ciancio + , M.A. Sapienza+, \\ A. Patanè+, A. Mistretta+, G.U. Di Maria ${ }^{+}$
}

Changes in respiratory drive account for the magnitude of dyspnoea during bronchoconstriction in asthmatics. S. Bellofiore, F.L.M. Ricciardolo, N. Ciancio, M.A. Sapienza, A. Patanè, A. Mistretta, G.U. Di Maria. C CERS Journals Ltd 1996.

ABSTRACT: To evaluate whether the interindividual differences in dyspnoea perceived by asthmatic subjects for the same level of airway narrowing could depend on different changes in respiratory drive, we assessed the relationship between changes in airway calibre, changes in neuromuscular output, and dyspnoea rate during progressive bronchoconstriction induced by methacholine.

We studied 18 asymptomatic asthmatic subjects (aged 18-36 yrs; 11 males and 7 females) with normal lung function. Dyspnoea (Borg scale), mouth occlusion pressure $(P 0.1)$, and forced expiratory volume in one second (FEV1) were measured at baseline and after inhalation of aerosols of doubling concentrations of methacholine (MCh).

The progressive bronchoconstriction induced by $\mathrm{MCh}$ was associated with a progressive increase both of $\boldsymbol{P} 0.1$ and dyspnoea. Dyspnoea score was linearly related either to the fall in FEV1, or to the increase in P0.1. However, the slope values of the relationship between dyspnoea score and the corresponding percent fall in FEV1 showed a large interindividual variability $(0.05-0.32$; coefficient of variability $(\mathrm{CoV})$ $43 \%)$. By contrast, the slope values of the relationship between dyspnoea score and the corresponding percent increase in $P_{0.1}$ ranged $0.02-0.05(\mathrm{CoV}=14 \%)$, indicating a more homogeneous response to dyspnoea for the same change in P0.1. At the highest MCh concentration, the dyspnoea score was linearly related to the corresponding change in $P 0.1(r=0.91 ; p<0.01)$, but not to the corresponding percentage fall in FEV1 $(r=0.28)$.

These results show that the interindividual differences in dyspnoea perceived by asthmatic subjects for the same level of airway narrowing are associated with different changes in respiratory drive during bronchoconstriction. Eur Respir J., 1996, 9, 1155-1159.
+Istituto di Malattie dell'Apparato Respiratorio, Università di Catania, Catania, Italy. *Servizio di Fisiopatologia Respiratoria, Ospedale "M. Ascoli-S. Tomaselli", Catania, Italy.

Correspondence: G.U. Di Maria Istituto di Malattie Respiratorie Università di Catania

Ospedale "M. Ascoli-S. Tomaselli"

Via Passo Gravina, 187

95125 Catania

Italy

Keywords: Asthma

bronchoconstriction

dyspnoea

respiratory drive

Received: July 271995

Accepted after revision January 211996
Dyspnoea is a common symptom experienced by asthmatic patients during episodes of bronchoconstriction. Although it has been reported that the magnitude of dyspnoea perceived is related to the severity of airflow obstruction $[1,2]$, patients with similar degrees of airflow obstruction experience different levels of dyspnoea during either spontaneously occurring asthma [3], or methacholine-induced bronchoconstriction [4]. The reason for such interindividual variability of intensity of dyspnoea is not known. The observation that patients with airflow obstruction have a higher threshold than normal subjects in detecting the addition of external resistive loads suggests that the presence of airway obstruction may be responsible for the underestimation of perceived dyspnoea [5]. Conflicting with this suggestion, however, is the observation that the presence of airflow obstruction does not result in an impaired perception of dyspnoea due to further airway narrowing induced by histamine [1].

It is known that methacholine-induced bronchoconstriction is associated with an increase in respiratory drive as assessed by mouth occlusion pressure [6, 7]. In addition, there is evidence that respiratory drive is a major determinant of the dyspnoea perceived during exercise or loaded breathing in normals $[8,9]$. However, the relationship between the intensity of dyspnoea and the changes in respiratory drive during progressive bronchoconstriction has not so far been evaluated. Therefore, in this study, we wanted to determine whether interindividual differences in dyspnoea perceived by asthmatic subjects for the same level of airway narrowing could depend on different changes in respiratory drive during bronchoconstriction. We sought to answer this question by assessing the relationship between changes in airway calibre, changes in neuromuscular output, and dyspnoea rate during progressive bronchoconstriction induced by methacholine in asymptomatic asthmatic subjects.

\section{Methods}

\section{Subjects}

Eighteen asthmatic out-patients referred to our asthma clinic for assessment of airway responsiveness were studied. Asthma was diagnosed in accordance with American 
Table 1. - Anthropometric, lung function data, and $\mathrm{PC}_{20} \mathrm{FEV}_{1}$ values of 18 asthmatic subjects

\begin{tabular}{|c|c|c|c|c|c|c|}
\hline Sex & $\begin{array}{l}\text { Age } \\
\text { yrs }\end{array}$ & $\begin{array}{l}\text { Height } \\
\mathrm{cm}\end{array}$ & $\begin{array}{c}\text { Weight } \\
\mathrm{kg}\end{array}$ & $\begin{array}{l}\text { FEV1 } \\
\% \text { pred }\end{array}$ & $\begin{array}{c}\mathrm{VC} \\
\% \text { pred }\end{array}$ & $\begin{array}{c}\mathrm{PC} 20 \mathrm{FEV}_{1} \\
\mathrm{mg} \cdot \mathrm{mL}^{-1}\end{array}$ \\
\hline M & 21 & 185 & 83 & 76 & 93 & 0.03 \\
\hline F & 34 & 155 & 64 & 93 & 98 & 0.03 \\
\hline M & 21 & 180 & 75 & 85 & 91 & 0.03 \\
\hline M & 19 & 187 & 85 & 119 & 100 & 0.60 \\
\hline M & 25 & 177 & 80 & 80 & 82 & 0.07 \\
\hline M & 18 & 157 & 57 & 112 & 120 & 1.49 \\
\hline M & 30 & 182 & 70 & 90 & 93 & 6.64 \\
\hline M & 17 & 170 & 62 & 78 & 80 & 0.48 \\
\hline F & 31 & 180 & 75 & 94 & 109 & 0.21 \\
\hline M & 22 & 154 & 49 & 86 & 91 & 0.45 \\
\hline $\mathrm{F}$ & 18 & 165 & 65 & 109 & 94 & 0.60 \\
\hline M & 21 & 180 & 70 & 80 & 86 & 0.06 \\
\hline M & 31 & 161 & 62 & 82 & 86 & 1.65 \\
\hline M & 27 & 190 & 102 & 121 & 117 & 0.16 \\
\hline $\mathrm{F}$ & 32 & 173 & 78 & 93 & 95 & 1.20 \\
\hline M & 33 & 150 & 45 & 86 & 96 & 0.04 \\
\hline M & 26 & 172 & 85 & 99 & 107 & 0.72 \\
\hline M & 36 & 184 & 81 & 91 & 118 & 0.03 \\
\hline Mean & 26 & 172 & 71 & 93 & 98 & $0.27 *$ \\
\hline$\pm \mathrm{SD}$ & 6 & 12 & 14 & 14 & 12 & \\
\hline
\end{tabular}

M: male; F: female; FEV1: forced expiratory volume in one second; VC: vital capacity; \% pred: percentage of predicted value; $\mathrm{PC}_{20} \mathrm{FEV} 1$ : cumulative provocative concentration of methacholine provoking a $20 \%$ fall of FEV1. *: geometric mean.

Thoracic Society (ATS) guidelines [10]. All subjects had a history of episodic wheezing and 12 were atopic. Anthropometric and lung function data of all subjects are presented in table 1. All subjects had baseline forced expiratory volume in one second $\left(\mathrm{FEV}_{1}\right)$ values above $75 \%$ of predicted. Subjects were asymptomatic and had not taken any medication for 2 weeks before the study. All subjects had been free of respiratory tract infections for at least 6 weeks prior to the study. No subject had ever had previous experience of sensory testing or was aware of the purpose of the study. The investigation was approved by the Research Ethics Committee of our hospital, and subjects gave their written consent to the methacholine provocation test.

\section{Study design}

After $5 \mathrm{~min}$ of resting breathing through the respiratory apparatus, subjects were asked to quantify their sensation of breathing effort by using a modified Borg scale. Thereafter, neuromuscular output was assessed by performing 10 measurements of mouth occlusion pressure $(P 0.1)$. Three reproducible forced expiratory manoeuvres, from which FEV1 values were derived, completed each set of measurements. The sensation of dyspnoea, $P 0.1$, and FEV1 were measured at baseline and $3 \mathrm{~min}$ after inhalation of saline and of each methacholine concentration. Postsaline values were used as control values.

\section{Methacholine challenge}

Methacholine hydrochloride ( $\mathrm{MCh}$ ) was dissolved in a phosphate-buffered isotonic solution $\left(\mathrm{NaH}_{2} \mathrm{PO}_{4} 1.808 \mathrm{~g}\right.$,
$\mathrm{NaH}_{2} \mathrm{PO}_{4} 7.576 \mathrm{~g}$ and $\mathrm{NaCl} 4.4 \mathrm{~g}$, in $1,000 \mathrm{~mL}$ of distilled water) and aerosolized using a Hudson nebulizer (Hudson Ltd, Temecula, CA, USA; output $0.16 \mathrm{~mL} \cdot \mathrm{min}^{-1}$ ) driven by a compressed air source ( 20 pounds per square inch (psi)). Aerosols of phosphate-buffered saline and of doubling concentrations of $\mathrm{MCh}$ were inhaled at tidal breathing for $2 \mathrm{~min}$ periods. The starting concentration of $\mathrm{MCh}$ was $0.03 \mathrm{mg} \cdot \mathrm{mL}^{-1}$, and the challenge was ended when a $50 \%$ fall in $\mathrm{FEV}_{1}$ was achieved or when the subject experienced excessive discomfort. The cumulative provocative concentration of MCh that provoked a $20 \%$ fall in FEV1 (PC20FEV1) was computed by linear interpolation from the concentration-response curve.

\section{Measurements}

Subjects were seated in a comfortable chair, with their nose occluded by a noseclip, and breathed via a mouthpiece through a pneumotachograph (Fleisch No. 3; Dynasciences, Blue Bell, PA, USA) mounted in series with a two-way breathing valve. The apparatus dead space was $168 \mathrm{~mL}$. Airflow $\left(V^{\prime}\right)$ was measured by the pneumotachograph connected to a differential pressure transducer (Statham PM45 $\pm 3.5 \mathrm{cmH}_{2} \mathrm{O}$; Hato Rey, PR). Mouth pressure $(P \mathrm{~m})$ was measured by means of a differential pressure transducer $\left(143 \mathrm{PC} 03 \mathrm{D} \pm 150 \mathrm{cmH}_{2} \mathrm{O}\right.$; Honeywell, Denver, CO, USA) connected through a noncompliant small-bore tube to the mouthpiece. Electrical signals of $V^{\prime}$ and $P \mathrm{~m}$ were amplified, filtered through a low-pass filter, converted into digital signals through a 12-bit analogue-to-digital converter (DT2801-A, Data Translation Inc., Marlboro, MA, USA) and sampled at $500 \mathrm{~Hz}$ using a personal computer. Data were stored on diskette for successive analysis.

$P 0.1$ was measured by occluding the inspiratory line of the breathing valve and by measuring the $P \mathrm{~m}$ generated during the first $0.1 \mathrm{~s}$ of the occluded inspiration. Occlusions were performed by silently turning a threeway tap during expiration so that the next inspiration was occluded from functional residual capacity. Occlusions were performed randomly so that the subject was not able to predict which breath would be occluded. Ten occlusions were performed, each being maintained for $0.25-0.30 \mathrm{~s}$.

Sensation of dyspnoea was assessed by using a modified Borg scale [9]. This is a category scale in which verbal notations describing increasing levels of breathing effort are anchored to numbers from 0 (none) to 10 (maximal). Subjects were asked to score their perceived breathing effort by pointing to a number whose verbal notation most appropriately described intensity of their sensation at that particular time. Subjects were allowed to select either whole numbers or fractions, and they were carefully instructed to score only their sensation of breathing effort and to ignore other sensory perception, such as dry mouth or sore throat.

\section{Data analysis}

Values are reported as mean \pm SEM, unless otherwise stated. The dyspnoea rates observed after each MCh inhalation were related either to the corresponding percentage 

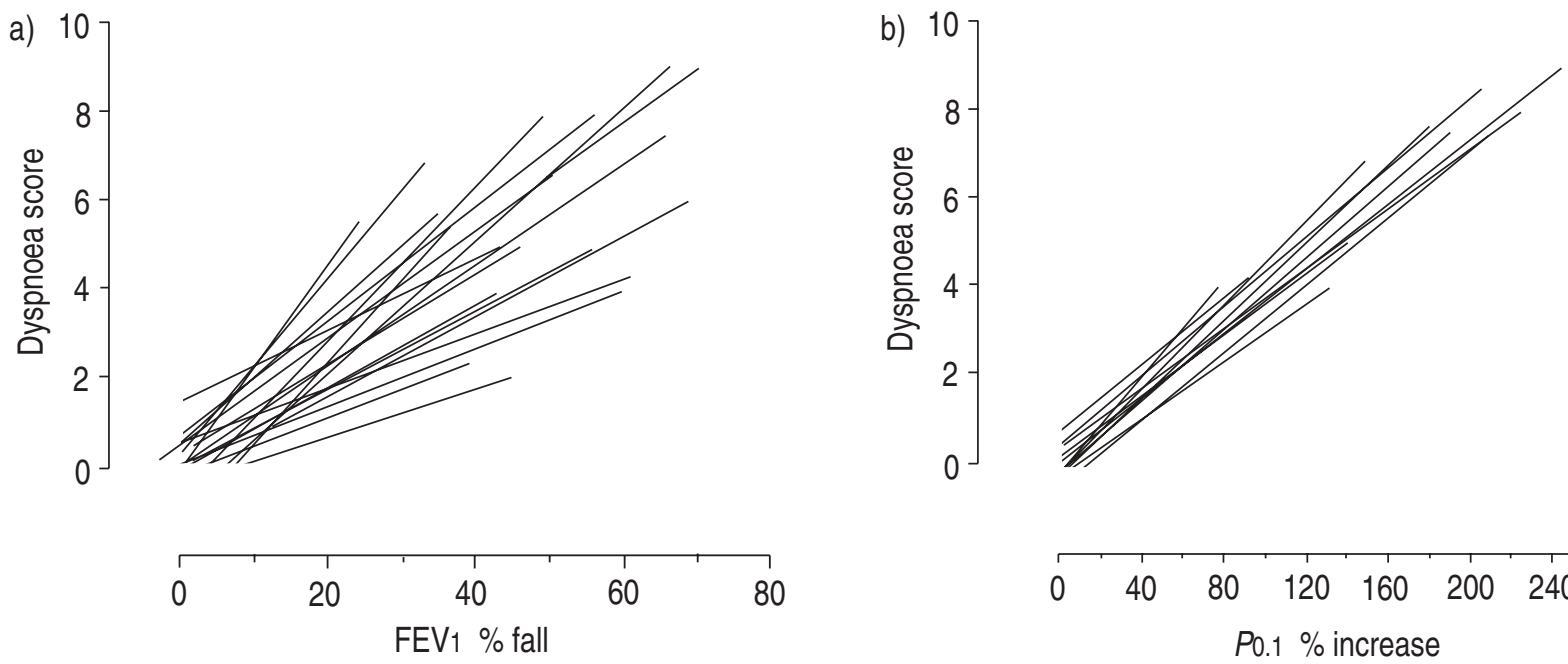

Fig. 1. - Individual regression lines between: a) percentage fall in FEV1 and dyspnoea score; and b) between percentage increase in $P 0.1$ and dyspnoea score. FEV1: forced expiratory volume in one second; $P 0.1$ : mouth occlusion pressure.

fall in FEV1 or to the corresponding percentage increase in $P 0.1$ by least squares linear regression. Coefficients of regression and slope values were calculated for each subject. The variability of the slope values of the relationships between dyspnoea score and changes in FEV1 or $P 0.1$ were compared by analysis of variance (ANOVA). The intensity of dyspnoea perceived at the $20 \%$ fall in FEV1 was linearly interpolated from the dyspnoea score versus percentage fall in FEV1 plot. Statistical significance was accepted for p-values less than 0.05

\section{Results}

The progressive bronchoconstriction induced by $\mathrm{MCh}$ was associated with progressive increases both in dyspnoea score and $P_{0.1}$ values. In each subject, dyspnoea score was linearly related to the percentage fall in FEV 1 , the individual coefficient of correlation ranging 0.72-0.99. The dyspnoea score was also linearly related to the percentage increase in $P_{0.1}$ in each subject (coefficient of correlation range 0.74-0.98). Correlations between dyspnoea score and percentage fall in FEV1 or percentage increase in $P_{0.1}$ were calculated over at least five data points. The individual regression lines for dyspnoea score versus percentage change in FEV1 or in $P_{0.1}$ are reported in figure 1. The individual slope values of the regression lines for dyspnoea score versus percentage change in FEV1 showed a large variability (coefficient of variation (CoV) 43\%) (fig. 2). In contrast, the variability of the slope values of the regression lines between dyspnoea score and percentage change in $P_{0.1}$ was significantly lower $(\mathrm{CoV} 14 \%$; $<<0.01)$ (fig. 2$)$.

The log-transformed values of PC20FEV1 were linearly related to the dyspnoea scores calculated at the $20 \%$ fall in FEV1 $(r=0.60 ; p<0.01)$, but not to the slope values of the relationship between dyspnoea and percentage fall in FEV1 ( $\mathrm{r}=0.39 \mathrm{NS}$ ).

At the highest MCh concentration, dyspnoea score was linearly related to the corresponding percentage increase in $P_{0.1}(\mathrm{r}=0.91 ; \mathrm{p}<0.01)$, but not to the corresponding percentage fall in $\mathrm{FEV}_{1}(\mathrm{r}=0.28$, fig. 3 ).

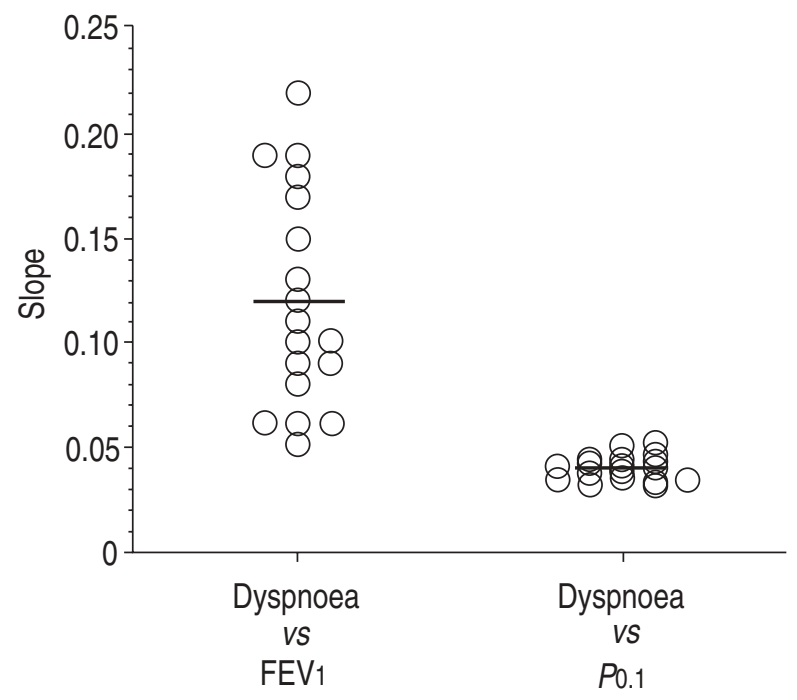

Fig. 2. - Individual slope values of the regression lines between dyspnoea score and percentage fall in FEV1, and between dyspnoea score and percentage increase in $P_{0.1}$. For definitions see legend to figure 1.

\section{Discussion}

This study shows that the interindividual differences in dyspnoea perceived by asthmatic subjects for the same level of airway narrowing depend on different changes in respiratory drive during bronchoconstriction. In fact, we have demonstrated that the intensity of dyspnoea sensation experienced by asthmatic subjects during progressive bronchoconstriction induced by methacholine is related both to the magnitude of airway narrowing and the increase in neuromuscular output. We also observed, however, a large interindividual variability of the dyspnoea perceived at any given level of airway narrowing, indicating that the perception of dyspnoea during bronchoconstriction is highly variable among asthmatic subjects. In contrast, we observed a lesser interindividual variability of the relationship between dyspnoea and changes in neuromuscular output, thus indicating that during progressive bronchoconstriction, for the same 

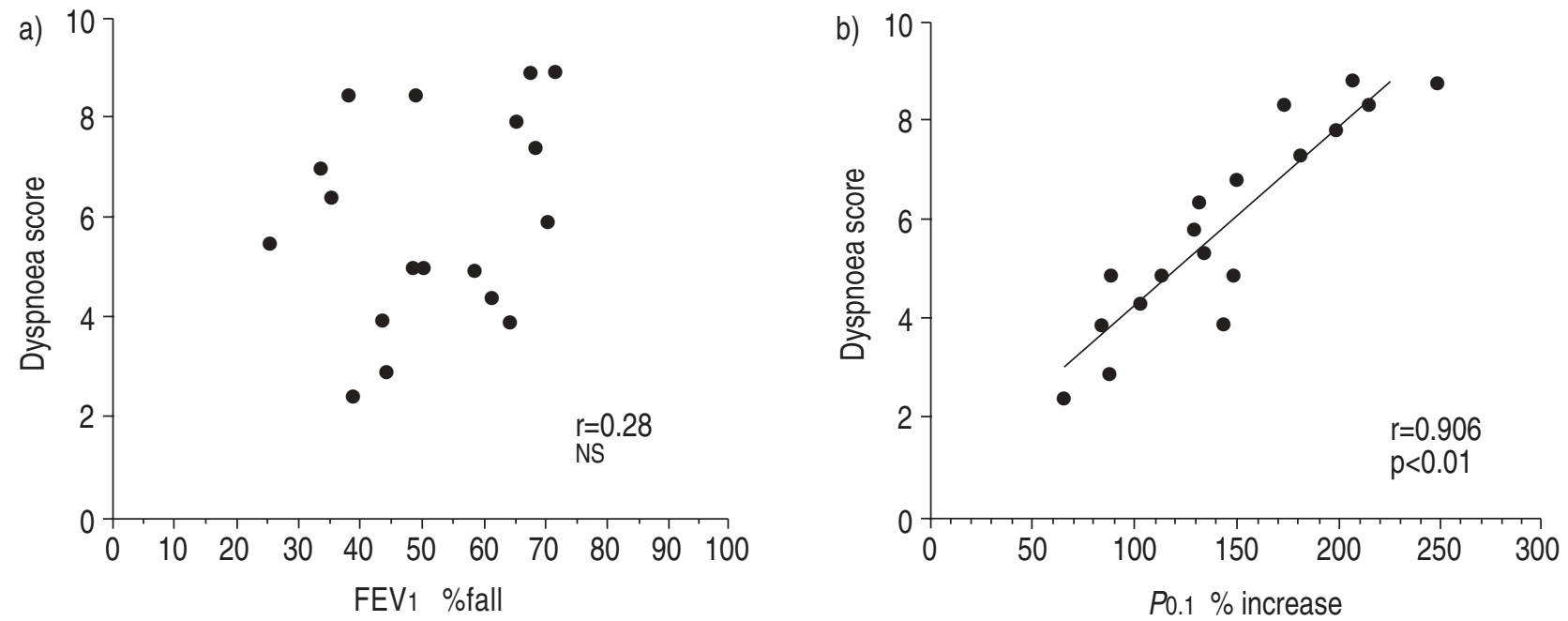

Fig. 3. - Relationship between: a) dyspnoea score and percentage fall in FEV1; or b) percentage increase in $P_{0.1}$ measured at the highest concentration of methacholine. For definitions see legend to figure 1.

change in neuromuscular output the intensity of perceived dyspnoea is the same among different subjects. Of relevance to the interpretation presented here is the observation that at the maximal degree of bronchoconstriction there was a significant relationship between dyspnoea score and the corresponding changes of P0.1, whereas no correlation was observed between dyspnoea score and the percentage fall in FEV1 (fig. 3).

The large interindividual variability in dyspnoea response to progressive airway narrowing observed in our study is similar to that previously reported by other investigators $[1,2,11,12]$. In particular, in the study by BURDON et al. [1], the average slope of the relationship between dyspnoea score, as measured by the Borg scale, and percentage fall in FEV1 was $0.13 \pm 0.06 \mathrm{SD}$, similar to the average value of $0.12 \pm 0.05$ SD observed in our study (fig. $2)$. In addition, our data provide further insight into the relationship between dyspnoea and changes in airway calibre, in that we demonstrated that dyspnoea score and changes in FEV1 were linearly related not only at $20 \%$ fall in FEV1 as reported previously $[1,12]$ but also at higher levels of bronchoconstriction.

Although it has long been recognized that the dyspnoea associated with a given level of bronchoconstriction varies widely among subjects [3, 4], the determinants of this variability are still poorly understood. It has been suggested that the differences in resting airway calibre could account for the differences in the sensation of dyspnoea associated with bronchoconstriction. It has been shown that asthmatics with airway obstruction, but not asthmatics with normal airway calibre, have an impaired perception both of external resistive loads [5] and carbachol-induced bronchoconstriction [13]. These findings have been interpreted as the result of an adaptation to prolonged stimulation of structures or mechanisms giving rise to the sensation of dyspnoea. In contrast with this interpretation, it has been observed that the presence of moderate airflow obstruction does not result in a blunted sensation of dyspnoea to further bronchoconstriction induced by histamine [1]. Our findings that only some of the subjects with normal resting airway calibre had a low dyspnoea response to bronchoconstriction indicate that resting airway calibre per se does not account for the variability in the perception of dyspnoea to progressive airway narrowing.

Another factor that has been suggested to be involved in the perception of dyspnoea is the degree of airway hyperresponsiveness. The significant relationship between the PC20FEV1 and the intensity of dyspnoea sensation at the $20 \%$ fall in FEV1 observed in this study, as well as in a previous study [1], indicates that subjects with higher airway hyperresponsiveness have a lower intensity of perceived dyspnoea during provoked bronchoconstriction. This finding has been interpreted as a tolerance to airway narrowing developed in response to increased frequency and severity of spontaneous asthma attacks [1]. On the other hand, it is also possible that subjects with higher hyperresponsiveness adopt breathing strategies that result in lower levels of dyspnoea.

Finally, recent evidence suggests that lung hyperinflation occurring during acute bronchoconstriction contributes to dyspnoea in asthma, and that the level of hyperinflation is partially responsible for the variability of perceived dyspnoea for a given level of bronchoconstriction [14]. This contribution of lung hyperinflation to perception of dyspnoea appears to be related to the changes in respiratory drive [14].

It is well-known that both spontaneous and provoked bronchoconstriction are associated with an increase in respiratory drive $[6,15]$. The increase in $P_{0.1}$ observed in the present study during MCh-induced bronchoconstriction was similar to that previously reported by others $[6,16]$, and by ourselves [7]. The increase in respiratory drive during bronchoconstriction has been suggested to be due to the activation of reflexes arising from muscular and joint receptors stimulated by hyperinflation [16, 17], and from airway receptors stimulated by inhaled substances and by bronchoconstriction [18-20]. The results of this study suggest that changes in respiratory drive are major determinants of the intensity of the sensation of dyspnoea experienced during progressive bronchoconstriction in asthmatic subjects. Our findings are in agreement with previous observations by KELSEN and co-workers [17]. These authors observed that both $P 0.1$ and the sensation of breathing effort increased to a greater extent during MCh-induced bronchoconstriction than during 
breathing against an external resistance, thus indicating that the sense of breathing effort is related to the intensity of the respiratory drive rather than to the resistive load applied to respiratory system. This is not surprising, in that it has been observed that asthmatic subjects adopt different ventilatory strategies in response both to airway narrowing $[15,21]$ and the addition of external resistive loads [17, 21]. On the other hand, it has been shown that the sensation of dyspnoea experienced during exercise [9], loaded breathing [8], or progressive bronchoconstriction [14] is a function of the intensity of respiratory drive. The importance of respiratory drive in determining the sensation of dyspnoea observed in our study is underlined by the recent observation that in patients with near-fatal asthma the reduced ability to perceive dyspnoea during resistive loading was associated to a blunted increase in $P_{0.1}$ to hypoxia [22].

In summary, the results of the present study indicate that in asymptomatic asthmatic subjects, the dyspnoea elicited by progressive bronchoconstriction is linearly related to the degree of airway narrowing and to the magnitude of changes in neuromuscular output. Most importantly, this study also shows that the intensity of the sensation of' dyspnoea for a given level of bronchoconstriction depends on the degree of activation of the neural motor command to the inspiratory muscles. These observations may have clinical implications in that they further support the concept that asthmatic subjects with blunted increases in respiratory drive, and therefore with lower intensity of dyspnoea perceived upon acute bronchoconstriction, are more prone to have fatal or near-fatal asthma attacks.

Acknowledgements: The authors thank D.F. Rochester for his valuable comments and suggestions.

\section{References}

1. Burdon JGW, Juniper EF, Killian FE, Hargreave FE, Campbell EJM. The perception of breathlessness in asthma. Am Rev Respir Dis 1982; 126: 825-828.

2. Dhand R, Kalra S, Malik SK. Use of visual analogue scales for assessment of the severity of asthma. Respiration 1988; 54: 255-262.

3. McFadden ER, Kiser R, De Groat WJ. Acute bronchial asthma. N Engl J Med 1973; 228 (5): 221-225.

4. Rubinfeld AR, Pain MCF. How mild is mild asthma? Thorax 1977; 32: 177-181.

5. Bonnel AM, Mathiot MJ, Jungas B, Grimaud C. Breathing discomfort in asthma: role of adaptation level. Bull Eur Physiopathol Respir 1987; 23: 23-29.

6. Mann J, Bradley CA, Anthonisen NR. Occlusion pressure in acute bronchospasm induced by methylcholine. Respir Physiol 1978; 33: 339-347.

7. Bellofiore S, Di Maria GU, Privitera S, Sapienza S, MilicEmili J Mistretta A. Endogenous opioids modulate the increase in ventilatory output and dyspnea during severe acute bronchoconstriction. Am Rev Respir Dis 1990; 142: 812-816.

8. Killian KJ, Bunces DD, Campbell EJM. The effect of the patterns of breathing on the perceived magnitude of added loads to breathing. J Appl Physiol: Respirat Environ Exercise Physiol 1982; 52: 578-584.

9. El-Manshawi A, Killiam KJ, Summers E, Jones NL. Breathlessness during exercise with and without resistive loading. J Appl Physiol 1986; 61: 896-905.

10. American Thoracic Society. Standards for the diagnosis and care of patients with chronic obstructive pulmonary disease (COPD) and asthma. Am Rev Respir Dis 1987; 136: 225-243.

11. Turcotte H, Boulet LP. Perception of breathlessness during early and late asthmatic responses. Am Rev Respir Dis 1993; 148: 514-518.

12. Boulet LP, Leblanc P, Turcotte H. Perception scoring of induced bronchoconstriction as an index of awareness of asthma symptoms. Chest 1994; 105: 1430-1433.

13. Orehek J, Beaupré A, Badier M, Nicoli MM, Delpierre S. Perception of airway tone by asthmatic patients. Bull Eur Physiopathol Respir 1982; 18: 601-607.

14. Lougheed MD, Lam M, Forkert L, Webb KA, O'Donnell DE. Breathlessness during acute bronchoconstriction in asthma: pathophysiologic mechanisms. Am Rev Respir Dis 1993; 148: 1452-1459.

15. Kassabian J, Miller KD, Lavietes MH. Respiratory centre output and ventilatory timing in patients with acute airway (asthma) and alveolar (pneumonia) disease. Chest 1982; 81: 536-543.

16. Millman RP, Slage DA, Peterson DD, Pack AL. Effect of aerosolized histamine on occlusion pressure and ventilation in humans. J Appl Physiol: Respirat Environ Exercise Physiol 1982; 53: 690-697.

17. Kelsen SG, Prestel TF, Cherniack NS, Chester EK. Comparison of respiratory responses to external resistive loading and bronchoconstriction in normal man. J Clin Invest 1981; 67: 1761-1768.

18. Bleeker ER, Cotton DJ, Fischer SP, Graf PD, Gold WM, Nadel JA. Rapid shallow breathing after inhaling histamine aerosol in exercising dogs. Am Rev Respir Dis 1976; 114: 909-915.

19. Miserocchi G, Trippenbach T, Mazzarelli M, Jaspar N, Hazucha M. The mechanism of rapid shallow breathing due to histamine and phenyldiguanide in cats and rabbits. Respir Physiol 1978; 32: 141-153.

20. Savoy J, Fleetham JA, Arnup ME, Anthonisen NR. Airway anesthesia and respiratory response to methacholine-induced bronchoconstriction. Respir Physiol 1981; 43: 59-68.

21. Kelsen SG, Fleegler B, Altose MD. The respiratory neuromuscular response to hypoxia, hypercapnia and obstruction to airflow in asthma. Am Rev Respir Dis 1979; 120: 517-527.

22. Kikuchi Y, Okabe S, Tamura G, et al. Chemosensitivity and perception of dyspnea in patients with a history of near-fatal asthma. N Engl J Med 1994; 330: 1329-1334. 